\title{
Effect of Adding Vildagliptin to Metformin on Antioxidant State, Inflammatory, and Atherothrombotic Markers in Newly Diagnosed Patients with Type 2 Diabetes Mellitus
}

\author{
Bassant M Mahboub ${ }^{1^{*}}$, Sahar M El-Haggar ${ }^{2}$, Yasser M Abdelraouf ${ }^{3}$, Gamal A Elazab ${ }^{2}$ \\ ${ }^{1}$ Drug and Poison Information Center, Faculty of Pharmacy, Tanta University, Tanta, Egypt; ${ }^{2}$ Clinical Pharmacy Department, \\ Faculty of Pharmacy, Tanta University, Tanta, Egypt; ${ }^{3}$ Internal Medicine Department, Faculty of Medicine, Tanta University, \\ Tanta, Egypt
}

\begin{abstract}
Objective: This study aimed to evaluate the effect of adding vildagliptin to metformin therapy on major CV risk parameters in newly diagnosed patients with type 2 diabetes mellitus (T2DM).

Methods: Forty three eligible patients were prospectively randomized to receive combined vildagliptin/ metformin therapy or metformin alone. Anthropometric measurements, blood pressure (BP), glycated hemoglobin (HbA1c), lipid profile, plasminogen activator inhibitor-1 (PAI-1), high sensitivity C-reactive protein (hsCRP), and total antioxidant capacity (TAC) were assessed at baseline and after 12 weeks.

Results: Forty patients completed the study (20 in each group). At baseline, no significant differences were observed between groups in all studied parameters. After 12 weeks, combined vildagliptin/metformin showed significant reductions in HbA1c ( $\Delta$ change: $-2.68 \pm 2.24$ versus $-1.37 \pm 1.8 \%, P=0.043$, respectively), systolic BP ( $\Delta$ change: $-12.5 \pm 13.03$ versus $-3.75 \pm 11.57 \mathrm{mmHg}, p=0.012$, respectively), diastolic BP ( $\Delta$ change: $-10.25 \pm 9.39$ versus $-2.5 \pm 9.39 \mathrm{mmHg}, p=0.009$, respectively), triglycerides ( $\Delta$ change: $-9.7 \pm 18.48$ versus $10.35 \pm 27.36 \mathrm{mg} / \mathrm{dl}$, $p=0.037$, respectively), and PAl-1( $\Delta$ change: $-7.93 \pm 17.11$ versus $3.9 \pm 19.39 \mathrm{ng} / \mathrm{ml}, p=0.048$, respectively) as compared to metformin monotherapy. No significant differences were observed between both groups regarding their effects on other studied parameters.

Conclusion: Adding vildagliptin to metformin resulted in a decrease in PAI-1, systolic and diastolic BP, triglycerides, and HbA1C with no significant changes in hs-CRP, TAC, and other lipid markers.
\end{abstract}

Keywords: Vildagliptin; Metformin; Cardiovascular risk; Type 2 diabetes mellitus.

\section{INTRODUCTION}

The global prevalence of type 2 diabetes mellitus (T2DM) is increasing rapidly with cardiovascular (CV) complications being the main cause of death and disability in affected patients [1]. Hyperglycemia promotes a number of metabolic changes accompanied by the pathogenesis and progression of atherosclerosis and vascular damage. It is associated with the generation of reactive oxygen species (ROS) with subsequent decreased antioxidant defenses, promoting inflammatory state, platelet hyperactivity, and endothelial dysfunction [2].
Moreover, CV risk factors of hypertension and atherogenic dyslipidemia are common among patients with T2DM [2].

Several inflammatory biomarkers have been demonstrated to be increased consequently to the hyperglycemic state [3]. From those is high-sensitivity C-reactive protein (hs-CRP) which has been recognized as an independent inflammatory predictor for CV events and risk assessment. It exerts proatherogenic effects implicated in the pathogenesis of atherosclerosis and endothelial dysfunction [4]. It is important to distinguish between traditional CRP and hs-CRP. The

\footnotetext{
${ }^{*}$ Correspondence to: Bassant M Mahboub, Drug and Poison Information Center, Faculty of pharmacy, Tanta University, Tanta, Egypt, 31111; Tel: +201205448976; Fax: +20 403335466; E-mail: bassantmaher88@yahoo.com

Received: August 14, 2019; Accepted: October 03, 2019; Published: October 10, 2019

Citation: Mahboub BM, El-Haggar SM, Abdelraouf YM, Elazab GA (2019) Effect of Adding Vildagliptin to Metformin on Antioxidant State, Inflammatory, and Atherothrombotic Markers in Newly Diagnosed Patients with Type 2 Diabetes Mellitus. J Diabetes Metab 10:834. doi: 10.35248/2155-6156.19.10.834
}

Copyright: (C) 2019 Mahboub BM, et al. This is an open-access article distributed under the terms of the Creative Commons Attribution License, which permits unrestricted use, distribution, and reproduction in any medium, provided the original author and source are credited. 
traditional CRP assay is a non-specific predictor used for the diagnosis and assessment of acute inflammation associated with neoplastic diseases and infections. While the hs-CRP assay is more sensitive, enables the detection of lower levels of CRP which indicate low-grade inflammation and exhibit a predictive value of future risk for developing CV disease (CVD) in diabetic and non-diabetic population [5]. According to the 2013 American College of Cardiology (ACC)/American Heart Association (AHA) guideline on the assessment of CV risk, hsCRP is valuable for the assessment and stratification of individuals at high CV risk and may be the subject of future guideline updates [6].

Chronic hyperglycemia also alters the coagulation process and leads to higher expression of plasminogen activator inhibitor-1 (PAI-1), an important regulatory element in fibrinolysis, with subsequent elevating the risk of atherothrombotic events $[7,8]$. All these metabolic features have been considered as the major CV risk factors which are clustering together leading finally to the diabetic vascular complications [2].

Metformin is strongly recommended as the first line therapy, if tolerated and not contraindicated, added to lifestyle modification for managing hyperglycemia in T2DM. For more glycemic control, stepwise addition strategy of other antihyperglycemic agents to metformin is generally accepted and preferred than initial combined metformin based therapy. Starting with the combination therapy may be considered in higher levels of basal glycemia [9]. Previously, metformin was shown to exert protective effects on several metabolic parameters and demonstrated CV benefits $[10,11]$.

Vildagliptin is one of the dipeptidyl peptidase-4 (DPP-4) inhibitors used for the management of T2DM. It inhibits the DPP-4 enzyme which rapidly degrades both incretin hormones: glucagon-like peptide-1 (GLP-1) and glucosedependent insulinotropic polypeptide (GIP). Active GLP-1 and GIP control glucose hemostasis mainly through a glucosedependent manner by acting on different sites of action [12]. Accumulative evidence reported possible beneficial effects of GLP-1 on the CV system. Moreover, beyond GLP-1, there are other multiple substrates for DPP-4 enzyme involved in regulating vascular function, inflammation, cell migration, and cell differentiation [13]. These findings may suggest the antiatherogenic and antiinflammatory properties of incretin based therapies illustrated in animal experimental studies [14]. However, these favorable effects have not been well studied in clinical setting especially for vildagliptin. Therefore, this study was designed to evaluate the effect of adding vildagliptin to metformin versus metformin monotherapy as initial therapies for newly diagnosed patients with T2DM focusing on the effect of vildagliptin on major CV risk markers.

\section{METHODS}

\section{Study design and patients}

This was a 12-week prospective randomized open-label interventional study. It was conducted in the Internal Medicine Outpatient Endocrinology Clinic, Tanta University
Hospitals, Tanta, Egypt. The ethical approval of the study was obtained from the National Research Ethics Committee of Tanta University. All participants signed an informed written consent prior to inclusion in the study. Inclusion criteria were newly diagnosed male and female patients with T2DM according to the American Diabetes Association (ADA) diagnostic criteria of diabetes who aged $\geq 18$ years with risk for developing atherosclerotic CV disease (ASCVD) based on traditional risk factors. Exclusion criteria were patients with renal impairment [estimated glomerular filtration rate (eGFR) $\leq$ $60 \mathrm{ml} / \mathrm{min} / 1.73 \mathrm{~m} 2$ ], known hepatic cell failure, decompensated heart requiring pharmacologic management, active malignancy on clinical bases, history of ASCVD, planned coronary or surgical interventions, known hypersensitivity to either of the study drug components, chronic inflammation, trauma or infection on clinical bases, and any of study treatment labeled contraindications. Pregnant women, those who were breastfeeding, and women using oral contraceptives were also excluded.

The study was initiated with a four-week titration period of metformin hydrochloride prior to randomization. Forty three eligible patients tolerated the maximum metformin dose of $2000 \mathrm{mg}$ daily after this titration period were randomized into two groups: group 1, 21 patients received metformin hydrochloride $1000 \mathrm{mg}$ twice daily (Glucophage ${ }^{\circledR}$, Minapharm Company, Egypt, under licence of Merck Santé Company, France) and group 2, 22 patients received combined therapy of vildagliptin $50 \mathrm{mg}$ plus metformin $1000 \mathrm{mg}$ twice daily (Vildagluse plus ${ }^{\circledR}$; vildagliptin $50 \mathrm{mg} /$ metformin hydrochloride 1000 mg, Inspire Pharma Company, Egypt) for 12 weeks. By the end of study, only 40 patients completed the study (20 patients in each group) as one patient was excluded from the metformin group due to dizziness and back pain while two other patients were missed in the combination group.

\section{Follow up visits}

All participants were monitored every two weeks. Lifestyle management with all its aspects were offered to all patients as recommended by the ADA at baseline and reinforced in each visit in both groups. All adverse events including hypoglycemia which is defined as blood glucose $<70 \mathrm{mg} / \mathrm{dl}$ were reported. Both symptomatic and asymptomatic hypoglycemic events were included. Baseline co-medications were advised to be continued with the same doses and frequencies during the study period.

\section{Anthropometric and blood pressure assessments}

Body weight was measured with light clothing and without shoes on a balance scale. Height was measured without shoes and caps using a meter that was supported on the balance scale and BMI was calculated as weight in kilograms divided by height squared in meters. Waist circumference was measured in centimeters using a flexible measuring tape in a horizontal plane midway between the iliac crest and the costal margin at the end of expiration. Systolic blood pressure (SBP) and diastolic blood pressure (DBP) were measured as millimeters mercury by a mercury sphygmomanometer while the patient 
was relaxed, comfortably seated, and with well supported arm.

\section{Biochemical assays}

All biochemical parameters were determined after 12 hours overnight fasting. Fasting blood samples were collected in the morning between $8.00 \mathrm{am}$ and $10.00 \mathrm{am}$. Seven $\mathrm{mL}$ of blood were withdrawn by a sterile syringe from the antecubital vein. Complete aseptic technique was used with safe disposal of materials used.

Glycated hemoglobin (HbA1c) was measured quantitatively by spectrophotometric method using commercial kits (Stanbio Laboratory Company, Texas, USA) [15]. Regarding serum lipid profile, total cholesterol (TC) was determined by enzymatic colorimetric method [16], triglycerides (TGs) was determined by enzymatic colorimetric method [17], and high-density lipoprotein cholesterol (HDL-C) was determined by precipitation method [18] using commercial kits (Spinreact Company, Girona, Spain). While, low-density lipoprotein cholesterol (LDL-C) was calculated using the Friedewald's formula: LDL-C (mg/dL)=TC (mg/dl) - [TGs $(\mathrm{mg} / \mathrm{dl}) / 5]-\mathrm{HDL}-\mathrm{C}$ $(\mathrm{mg} / \mathrm{dl})$ in case of TGs concentration is $<400 \mathrm{mg} / \mathrm{dl}$ [19]. Serum level of hs-CRP was determined by a solid phase enzyme-linked immunosorbent assay (ELISA) using commercial kits (Diagnostic Automation Inc. company, California,USA) [20]. The total antioxidant capacity (TAC) was determined by enzymatic colorimetric method using commercial kits (Biodiagnostic Company, Giza, Egypt) [21]. The level of PAl-1 was determined by ELISA assay using commercial kits (Affymetrix eBioscience company, Vienna, Austria) [22].

All participants were assessed for the anthropometric data, SBP, DBP, and biochemical parameters twice: at baseline (after titration period) and at the endpoint of week 12 .

\section{Statistical analysis}

Results were analyzed using the Statistical Package for Social Science (SPSS) version 22 (August 2013), IBM corporation software group, Chicago, USA. Data were expressed as mean \pm standard deviation (SD) for continuous variables and percentage for categorical variables. Comparisons within and between groups were performed using Student's t-test. Chisquare test was used for comparisons between categorical variables. Binary logistic regression analysis was performed to illustrate the effect of independent predictors (vildagliptin/ metformin versus metformin and change in $\mathrm{HbA1c}$ levels) on the outcome of the significantly changed biological markers. In all cases, a two-tailed $p$-value less than 0.05 was considered statistically significant.

\section{RESULTS}

\section{Baseline characteristics of patients}

No statistically significant differences were observed between both studied groups in demographic, anthropometric, and all other studied parameters at baseline (Table 1).

Table 1: Baseline characteristics of the patients.

\begin{tabular}{|c|c|c|c|}
\hline Parameters & Metformin group $(n=20)$ & Vildagliptin/metformin group $(n=20)$ & p-value \\
\hline Number (male/female) & $6 / 14$ & $7 / 13$ & 0.74 \\
\hline Smoking \% & $10 \%$ & $15 \%$ & 0.63 \\
\hline Age (years) & $54.45 \pm 5.05$ & $53.2 \pm 6.82$ & 0.51 \\
\hline Height (m) & $1.6 \pm 0.05$ & $1.62 \pm 0.06$ & 0.26 \\
\hline Body weight (kg) & $91.21 \pm 12.56$ & $91.15 \pm 11.74$ & 0.99 \\
\hline BMI (kg/m2) & $35.46 \pm 4.82$ & $34.79 \pm 5.72$ & 0.69 \\
\hline Waist circumference (cm) & $123.65 \pm 10.67$ & $121.6 \pm 9.67$ & 0.53 \\
\hline \multicolumn{4}{|l|}{ Baseline medications (\%): } \\
\hline Statins & $45 \%$ & $50 \%$ & 0.75 \\
\hline \multicolumn{4}{|l|}{ Antihypertensive } \\
\hline ACE inhibitors & $20 \%$ & $10 \%$ & 0.38 \\
\hline ARBs & $10 \%$ & $10 \%$ & 1 \\
\hline CCBs & 0 & $5 \%$ & 0.31 \\
\hline
\end{tabular}




\begin{tabular}{lccc}
\hline B-blockers & $5 \%$ & $0 \%$ & 0.31 \\
\hline Antiplatelet & $10 \%$ & $9.99 \pm 1.35$ & 0.15 \\
\hline HbA1c (\%) & $9.53 \pm 1.3$ & $4.71 \pm 2.5$ & 0.28 \\
\hline hs-CRP (mg/L) & $3.94 \pm 2.22$ & $191 \pm 33.34$ & 0.31 \\
\hline TC (mg/dl) & $186.25 \pm 27.34$ & $145.55 \pm 23.98$ & 0.28 \\
\hline TGs $(\mathrm{mg} / \mathrm{dl})$ & $137.6 \pm 21.51$ & $45.1 \pm 10.6$ & 0.19 \\
\hline HDL-C (mg/dl) & $48.95 \pm 7.19$ & $116.79 \pm 39.37$ & 0.53 \\
\hline LDL-C (mg/dl) & $109.78 \pm 30.55$ & $85.95 \pm 18.03$ & 0.91 \\
\hline PAl-1 (ng/ml) & $85.35 \pm 14.78$ & $0.98 \pm 0.36$ & 0.23 \\
\hline TAC (mM/L) & $0.85 \pm 0.35$ & $125.5 \pm 17.39$ & 0.81 \\
\hline SBP (mmHg) & $126.75 \pm 14.89$ & $85.5 \pm 10.5$ & 0.39 \\
\hline DBP (mmHg) & $83 \pm 7.33$ & & \\
\hline
\end{tabular}

Data are presented as means \pm SD for continuous variables and percentage for categorical variables. BMI: body mass index; ACE: angiotensin converting enzyme; ARBs: angiotensin receptor blockers; CCBs: calcium channel blockers. HbA1c: glycated hemoglobin A1c; hs-CRP: highsensitivity C-reactive protein; TC: total cholesterol; TGs: triglycerides; HDL-C: high-density lipoprotein cholesterol; LDL-C: low-density lipoprotein cholesterol; PAI-1: plasminogen activator inhibitor-1; TAC: total antioxidant capacity; SBP: systolic blood pressure; DBP: diastolic blood pressure.

Effects on anthropometric and BP measurements

After 12 weeks of metformin therapy, there were no significant changes observed in anthropometric measurements, SBP, and DBP compared to their levels before treatment. After combined vildagliptin/metformin therapy, there were significant reductions in waist circumference, SBP, and DBP levels, while there were no significant changes in body weight and BMI. When comparing the two groups after treatment, there were no significant differences observed in anthropometric measurements, there were significant differences between both treatment groups in SBP ( $\Delta$ change: $-12.5 \pm 13.03 \mathrm{mmHg}$ after combined therapy versus $-3.75 \pm$ $11.57 \mathrm{mmHg}$ after metformin monotherapy, $p=0.012$ ) and DPB ( $\Delta$ change: $-10.25 \pm 9.39$ after combined therapy versus $-2.5 \pm$ $9.39 \mathrm{mmHg}$ after monotherapy, $p=0.009$ ) (Table 2).

Table 2: Effect of treatment on anthropometric and BP measurements.

\begin{tabular}{|c|c|c|c|c|c|c|c|}
\hline \multirow{2}{*}{ Parameters } & \multicolumn{2}{|c|}{ Metformin group } & \multirow[t]{2}{*}{ P1 } & \multicolumn{2}{|c|}{ Vildagliptin/metformin group } & \multirow[t]{2}{*}{ P1 } & \multirow[t]{2}{*}{$\mathbf{P 2}$} \\
\hline & Baseline & After 12 weeks & & Baseline & After 12 weeks & & \\
\hline Body weight (kg) & $91.21 \pm 12.56$ & $90.7 \pm 11.87$ & 0.46 & $91.15 \pm 11.74$ & $90.29 \pm 10.92$ & 0.26 & 0.91 \\
\hline BMI $\left(\mathrm{kg} / \mathrm{m}^{2}\right)$ & $35.46 \pm 4.82$ & $35.27 \pm 4.59$ & 0.45 & $34.79 \pm 5.72$ & $34.48 \pm 5.51$ & 0.25 & 0.63 \\
\hline $\begin{array}{l}\text { Waist circumference } \\
(\mathrm{cm})\end{array}$ & $123.65 \pm 10.67$ & $123.05 \pm 10.35$ & 0.28 & $121.6 \pm 9.67$ & $120.05 \pm 9.83$ & 0.024 & 0.35 \\
\hline SBP (mmHg) & $126.75 \pm 14.89$ & $123 \pm 12.18$ & 0.16 & $125.5 \pm 17.39$ & $113 \pm 11.74$ & 0.000 & 0.012 \\
\hline DBP (mmHg) & $83 \pm 7.33$ & $80.5 \pm 5.83$ & 0.25 & $85.5 \pm 10.5$ & $75.25 \pm 6.17$ & 0.000 & 0.009 \\
\hline
\end{tabular}

Data are presented as means \pm SD. BMI: body mass index; SBP: systolic blood pressure; DBP: diastolic blood pressure; P1: $p$-value within group; P2: $p$-value between groups after treatment. 
Effects on $\mathrm{HbA1c}$ and lipid profile

After metformin therapy, there was a significant reduction in $\mathrm{HbA1c}$ with no significant changes in lipid parameters. While after combined vildagliptin/metformin therapy, there were significant improvements in $\mathrm{HbA1c}$, TGs, HDL-C, there were no significant changes in TC and LDL-C. When comparing the two groups after treatment, the reduction of $\mathrm{HbA} 1 \mathrm{c}$ in combined group was significantly greater than that in metformin group ( $\Delta$ change after 12 weeks: $-2.68 \pm 2.24 \%$ versus $-1.37 \pm 1.8 \%$, $\mathrm{P}$
$=0.043$, respectively). In addition, $\mathrm{HbA} 1 \mathrm{c}$ was $<7 \%$ in $45 \%$ of cases in combined group compared to $30 \%$ of cases in metformin group with no statistically significant differences between both groups. There were no significant differences between both groups in lipid parameters except for TGs ( $\Delta$ change: $-9.7 \pm 18.48 \mathrm{mg} / \mathrm{dl}$ after combined therapy versus $10.35 \pm 27.36 \mathrm{mg} / \mathrm{dl}$ after metformin monotherapy with $p=0.037$ ) (Table 3).

Table 3: Effect of treatment on HbA1c and lipid profile.

\begin{tabular}{|c|c|c|c|c|c|c|c|}
\hline \multirow{2}{*}{ Parameter } & \multicolumn{2}{|c|}{ Metformin group } & \multirow[t]{2}{*}{ P1 } & \multicolumn{2}{|c|}{ Vildagliptin/metformin group } & \multirow[t]{2}{*}{ P1 } & \multirow[t]{2}{*}{ P2 } \\
\hline & Baseline & After 12 weeks & & Baseline & After 12 weeks & & \\
\hline $\mathrm{HbA} 1 \mathrm{c} \%$ & $9.53 \pm 1.3$ & $8.16 \pm 1.27$ & 0.003 & $9.99 \pm 1.35$ & $7.31 \pm 1.28$ & 0.000 & 0.043 \\
\hline $\mathrm{TC}(\mathrm{mg} / \mathrm{dl})$ & $186.25 \pm 27.34$ & $181.15 \pm 20.01$ & 0.43 & $191 \pm 33.34$ & $176.1 \pm 12.59$ & 0.054 & 0.35 \\
\hline TGs (mg/dl) & $137.6 \pm 21.51$ & $147.95 \pm 17.08$ & 0.11 & $145.55 \pm 23.98$ & $135.85 \pm 18.33$ & 0.03 & 0.037 \\
\hline HDL-C (mg/dl) & $48.95 \pm 7.19$ & $49.5 \pm 5.16$ & 0.75 & $45.1 \pm 10.6$ & $49.9 \pm 5.24$ & 0.049 & 0.81 \\
\hline LDL-C (mg/dl) & $109.78 \pm 30.55$ & $102.06 \pm 22.12$ & 0.28 & $116.79 \pm 39.37$ & $99.03 \pm 13.88$ & 0.06 & 0.61 \\
\hline
\end{tabular}

Data are presented as means \pm SD. HbA1c: glycated hemoglobin; TC: total cholesterol; TGs: triglycerides; HDL-C: high-density lipoprotein cholesterol; LDL-C: low-density lipoprotein cholesterol; P1: $p$-value within group; P2: $p$-value between groups after treatment.

Effects on, TAC, hs-CRP, and PAI-1

After 12 weeks of treatment, metformin therapy showed significant increase in TAC ( $\Delta$ change: $0.18 \pm 0.22 \mathrm{mM} / \mathrm{L}$, $p=0.002$ ), significant decrease in hs-CRP ( $\Delta$ change: $-1.11 \pm$ $1.78 \mathrm{mg} / \mathrm{L}, p=0.012$ ), and small non- significant increase in PAl-1 ( $\Delta$ change: $3.9 \pm 19.39 \mathrm{ng} / \mathrm{ml}, p=0.38$ ). The combined therapy significantly increased TAC ( $\Delta$ change: $0.21 \pm 0.23$
$\mathrm{mM} / \mathrm{L}, p=0.001$ ), significantly decreased hs-CRP ( $\Delta$ change: $1.9 \pm 3.64 \mathrm{mg} / \mathrm{L}, p=0.031)$, and reduced PAl-1 non-significantly ( $\Delta$ change: $-7.93 \pm 17.11 \mathrm{ng} / \mathrm{ml}, p=0.052$ ). By comparing the two groups, there were no significant differences observed in TAC and hs-CRP, while there were significant changes in PAI-1 $(p=0.048)$ (Table 4).

Table 4: Effect of treatment on TAC, hs-CRP, and PAI-1.

\begin{tabular}{|c|c|c|c|c|c|c|c|}
\hline \multirow{2}{*}{ Parameter } & \multicolumn{2}{|c|}{ Metformin group } & \multirow[t]{2}{*}{ P1 } & \multicolumn{2}{|c|}{ Vildagliptin/metformin group } & \multirow[t]{2}{*}{ P1 } & \multirow[t]{2}{*}{$\mathbf{P 2}$} \\
\hline & Baseline & After 12 weeks & & Baseline & After 12 weeks & & \\
\hline TAC (mM/L) & $0.85 \pm 0.35$ & $1.03 \pm 0.36$ & 0.002 & $0.98 \pm 0.36$ & $1.19 \pm 0.46$ & 0.001 & 0.23 \\
\hline hs-CRP (mg/L) & $3.94 \pm 2.22$ & $2.83 \pm 1.48$ & 0.012 & $4.71 \pm 2.5$ & $2.81 \pm 2.65$ & 0.031 & 0.97 \\
\hline PAl-1 (ng/ml) & $85.35 \pm 14.78$ & $89.25 \pm 15.08$ & 0.38 & $85.95 \pm 18.03$ & $78.03 \pm 19.44$ & 0.052 & 0.048 \\
\hline
\end{tabular}

Data are presented as means \pm SD. TAC: total antioxidant capacity; hs-CRP: high-sensitivity C-reactive protein; PAI-1: plasminogen activator inhibitor-1; P1: $p$-value within group; P2: $p$-value between groups after treatment.

Logistic regression analysis

Results from binary logistic regression analysis revealed that adding vildagliptin to metformin was independently associated with the significant reduction in TGs [exponentiation of the $B$ coefficient: $\operatorname{Exp}(B)=5.35, p=0.023$ ] rather than that for the change in $\mathrm{HbA} 1 \mathrm{c}$ levels $[\operatorname{Exp}(B)=5.43$, $p=0.16]$. On the other hand, neither treatment modality nor changes in $\mathrm{HbA} 1 \mathrm{c}$ levels were independently associated with the reduction in PAI-1 levels between groups at the end of the study period $(p \geq 0.05)$. 


\section{Treatment adverse effects}

During treatment period, both treatment lines were generally well tolerated with no serious side effects. A number of mild side effects were recorded as illustrated in Figure 1 with no statistically significant differences between both studied groups.

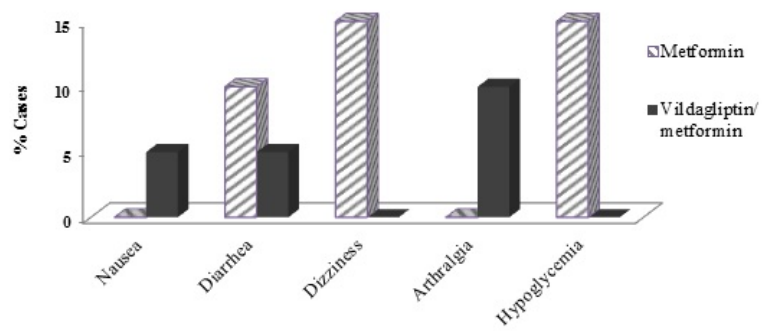

Figure 1: Percent of recorded adverse effects.

\section{DISCUSSION}

The main findings of this study were that adding vildagliptin to metformin therapy reduced SBP, DBP, HbA1c, TGs, and PA1-1 levels as compared to metformin monotherapy with no risk of hypoglycemic events in newly diagnosed patients with T2DM. Vildagliptin showed no effects on TAC, hs-CR, and other lipid parameters.

Previous studies demonstrated that combination therapy of metformin plus vildagliptin significantly reduced $\mathrm{HbA1c}$ levels compared to monotherapy of each one [23,24]. Results from the present study supported these findings. Underlying mechanism may be mediated by the glycemic control augmentation of vildagliptin and metformin with the enhanced stimulation of postprandial insulin secretion. In addition, metformin beyond its known action of reducing hepatic glucose output and improving insulin resistance has been shown to stimulate the GLP-1 biosynthesis in preclinical studies [25]. Furthermore, the levels of intact GLP-1 can be preserved by the inhibitory action of vildagliptin on DPP-4 enzyme.

While, clinical data regarding the effect of vildagliptin on SBP and DBP levels remain uncertain and driven mainly form preclinical and mechanistic studies. According to the present study, vildagliptin therapy for 12 weeks was associated with significant reductions in SBP and DBP levels. This effect may contribute to a great advantage for patients with T2DM. The vasodilatory effect of vildagliptin may be mediated by the effect of GLP-1 on the nitric oxide production with endothelium dependent relaxations as shown by Liu et al [26]. Moreover, vildagliptin has been shown to exert diuretic effects according to recent preclinical data [27]. In addition, Shah et al. demonstrated the direct effect of alogliptin therapy on the nitric oxide system, independent of GLP-1, with subsequent vascular tone relaxation in animal models [28].

Atherogenic dyslipidemia is a metabolic disorder of hyperglycemia which increases the CV risk in diabetic population [29]. In addition, hypertriglyceridemia was shown to elevate the risk of myocardial infarction, ischemic heart disease, and death as reported by the prospective cohort study in Denmark [30]. The clinical implications of the effect of vildagliptin therapy on lipoprotein metabolism are still controversial. According to the present study, positive effects of vildagliptin on the lipid profile levels were shown. After 12 weeks, vildagliptin was shown to exert a significant reduction in fasting levels of TGs beyond its glycemic control. In addition, the combined therapy was associated with a trend for better improvement of the other studied lipid parameters as compared to metformin monotherapy but without reaching significance.

These findings are in consistence with Matikainen et al. who demonstrated that vildagliptin therapy for four weeks reduced postprandial plasma TGs and apolipoprotein B48 in drug naïve patients with T2DM [31]. Hsieh et al. also provided the evidence of DPP-4 inhibitors effect on controlling postprandial lipoprotein biosynthesis and secretion through GLP1 receptor signaling in animal model [32]. On the other hand, slight nonsignificant increase in fasting TGs was shown after metformin therapy. Further explanations of the underlying cause are needed.

According to the atherothrombotic CV risk factor, PAI-1, data from the recent systematic metaanalysis proved that lowering PAI-1 levels is associated with decreased ASCVD risk [33]. This study demonstrated that combined therapy was associated with significant reduction in PAI-1 levels compared with metformin therapy which the later was associated with slight increase in PAI-1 levels. These findings are in consistence with the work by Strózik et al. work who found that PAI-1 levels increased in patients treated with metformin while these levels decreased after adding vildagliptin to the metformin therapy [34]. Underlying mechanism of the favorable effect of vildagliptin on PAI-1 is still unexplained and unclear. However it may be supported by data from previous preclinical studies which demonstrated the effect of vildagliptin on the reduction of PAl-1 gene expression in rat thoracic aorta and retina $[35,36]$.

Hypoglycemia is associated with an increased risk of CVD [37]. Unfortunately, most commonly used antihyperglycemic agents have been reported to be associated with increased risk of hypoglycemia [38,39]. In this work, both treatment approaches were shown to be generally well tolerated. No case of hypoglycemia was reported in vildagliptin/metformin group compared to three cases (15\%) in metformin group during the treatment period. Previous literatures supported that metformin monotherapy is associated with hypoglycemic risk of zero to $21 \%$ [38].

On the other hand, incretin hormones regulate glucose hemostasis in glucose dependent manner lowering the probability of hypoglycemia [40]. In addition, according to previous clinical data, vildagliptin was shown to inhibit glucagon levels during the hyperglycemic state while it sustained glucagon counter-regulation at lower levels of glycemia [41].

Moreover, Results from this work revealed that vildagliptin is weight neutral and hasn't been associated with increasing 
BMI. These findings are in consistence with previous studies $[42,43]$. Regarding the central obesity, Valerio et al. demonstrated a positive correlation between DPP-4 enzyme levels and central fat distribution in patients with familial partial lipodystrophy type 2 [44]. Thus, inhibition of DPP-4 enzyme may be associated with central fat redistribution and waist circumference reduction. Our work revealed that the combined therapy was associated with a significant reduction in waist circumference while as compared to metformin therapy this reduction didn't reach the significance. Similarly, vildagliptin improved hs-CRP and TAC levels without significance.

\section{CONCLUSION}

In conclusion, vildagliptin was shown to be weight neutral, with no risk of hypoglycemia, and with a good impact on some atherogenic risk parameters including SBP, DBP, TGs, and PAI-1. Vildagliptin therapy did not affect hs-CRP and TAC levels significantly. These findings may reflect possible beneficial effects of adding vildagliptin to metformin therapy for more glycemic control and with possible additional CV risk benefits in patients with T2DM and CV risk.

\section{STUDY LIMITATIONS}

The sample size and the follow up duration could have been larger to prove better significance. Otherwise these limitations, this study is important because it highlighted the protective effects of vildagliptin on certain CV risk markers that have not been well studied before particularly for the Egyptian population. We encourage further large randomized controlled trials to be conducted to confirm our results and explore more beneficial aspects of vildagliptin. Other cardiac markers of CVD could be tried and correlated with the drugs specified.

\section{ACKNOWLEDGMENTS}

The authors thank Professor Amal El-Bendary, Clinical Pathology Department, Faculty of Medicine, Tanta University, Egypt, for her co-operation in laboratory analysis. Great thanks for Dr. Ibrahim Kabbash, Professor of Public Health and Biostatistics, Faculty of Medicine, Tanta University, Egypt, for his assistance in the regression analysis.

\section{CONFLICTS OF INTEREST}

There were no conflicts of interest that any of the authors may have.

\section{REFERENCES}

1. Chaudhury A, Duvoor C, Reddy Dendi VS, Kraleti S, Chada A, Ravilla $R$, et al. Clinical Review of Antidiabetic Drugs: Implications for Type 2 Diabetes Mellitus Management. Front Endocrinol (Lausanne). 2017;8:6.

2. Leon BM, Maddox TM. Diabetes and cardiovascular disease: Epidemiology, biological mechanisms, treatment recommendations and future research. World J Diabetes. 2015;6:1246-1258.
3. Vinagre I, Sánchez-Quesada JL, Sánchez-Hernández J, Santos D, Ordoñez-Llanos J, De Leiva A, et al. Inflammatory biomarkers in type 2 diabetic patients: effect of glycemic control and impact of Idl subfraction phenotype. Cardiovasc Diabetol. 2014;13:34.

4. Yousuf O, Mohanty BD, Martin SS, Joshi PH, Blaha MJ, Nasir K, et al. High-sensitivity $\mathrm{C}$-reactive protein and cardiovascular disease: a resolute belief or an elusive link? J Am Coll Cardiol. 2013;62:397-408.

5. Ridker PM, Libby $P$, Buring JE. Risk markers and the primary prevention of cardiovascular disease. In: Zipes DP, Libby $\mathrm{P}$, Bonow RO, Mann DL, Tomaselli GF (Ed.). Braunwald's Heart Disease: A Textbook of Cardiovascular Medicine. 11th ed. New York, NY: Elsevier. 2019;876-909.

6. Goff DC Jr, Lloyd-Jones DM, Bennett G, Coady S, D'Agostino RB Sr, Gibbons R, et al. 2013 ACC/AHA guideline on the assessment of cardiovascular risk: a report of the American College of Cardiology/American Heart Association Task Force on Practice Guidelines. J Am Coll Cardiol 2014;63:2935-2959.

7. Paneni F, Beckman JA, Creager MA, Cosentino F. Diabetes and vascular disease: pathophysiology, clinical consequences, and medical therapy: part I, Eur Heart J. 2013;34:2436-2443.

8. Vaughan DE. PAI-1 and atherothrombosis, J Thromb Haemost. 2005;3:1879-1883.

9. Davies MJ, D'Alessio DA, Fradkin J, Kernan WN, Mathieu C, Mingrone $G$, et al. Management of hyperglycemia in type 2 diabetes, 2018. A consensus report by the American Diabetes Association (ADA) and the European Association for the Study of Diabetes (EASD). Diabetes Care. 2018;41:2669-2701.

10. Scarpello JH, Howlett HC. Metformin therapy and clinical uses. Diab Vasc Dis Res. 2008;5:157-167.

11. UK Prospective Diabetes Study (UKPDS) Group. Effect of intensive blood-glucose control with metformin on complications in overweight patients with type 2 diabetes (UKPDS 34). Lancet. 1998;352:854-865.

12. Ahrén B, Schweizer A, Dejager S, Villhauer EB, Dunning BE, Foley $J E$. Mechanisms of action of the dipeptidyl peptidase- 4 inhibitor vildagliptin in humans. Diabetes Obes Metab. 2011;13:775-783.

13. Kawanami D, Matoba K, Sango K, Utsunomiya K. Incretin-Based Therapies for Diabetic Complications: Basic Mechanisms and Clinical Evidence. Int J Mol Sci. 2016;17:1223.

14. Hirano T, Mori Y. Antiatherogenic and antiinflammatory properties of glucagonlike peptide1, glucosedependent insulinotropic polypepide, and dipeptidyl peptidase 4 inhibitors in experimental animals. J Diabetes Investig. 2016;7:80-86.

15. Trivelli LA, Ranney HM, Lai HT. Hemoglobin components in patients with diabetes mellitus. $N$ Engl J Med. 1971;284:353-357.

16. Meiattini F, Prencipe L, Bardelli F, Giannini G, Tarli P. The 4hydroxybenzoate/4-aminophenazone chromogenic system used in the enzymic determination of serum cholesterol. Clin Chem. 1978;24:2161-2165.

17. Fossati P, Prencipe L. Serum triglycerides determined colorimetrically with an enzyme that produces hydrogen peroxide. Clin Chem. 1982;28:2077-2080.

18. Grove TH. Effect of reagent $\mathrm{pH}$ on determination of high-density lipoprotein cholesterol by precipitation with sodium phosphotungstate-magnesium. Clin Chem. 1979;25:560-564.

19. Friedewald WT, Levy RI, Fredrickson DS. Estimation of the concentration of low-density lipoprotein cholesterol in plasma, without use of the preparative ultracentrifuge. Clin Chem. 1972;18:499-502.

20. Wu TL, Tsao KC, Chang CP, Li CN, Sun CF, Wu JT. Development of ELISA on microplate for serum C-reactive protein and 
establishment of age-dependent normal reference range. Clin Chim Acta. 2002;322:163-168.

21. Koracevic D, Koracevic G, Djordjevic V, Andrejevic S, Cosic V. Method for the measurement of antioxidant activity in human fluids, J Clin Pathol. 2001;54:356-361.

22. Grebenschikov N, Geurts-Moespot A, De Witte H, Heuvel J, Leake $R$, Sweep $F$, et al. A sensitive and robust assay for urokinase and tissue-type plasminogen activators (UPA and tPA) and their inhibitor type I (PAI-1) in breast tumor cytosols. Int J Biol Markers. 1997;12:6-14.

23. Bosi E, Camisasca RP, Collober C, Rochotte E, Garber AJ. Effects of vildagliptin on glucose control over 24 weeks in patients with type 2 diabetes inadequately controlled with metformin. Diabetes Care. 2007;30:890-895.

24. Rosales R, Abou Jaoude E, Al-Arouj M, Fawwad A, Orabi A, Shah $P$, et al. Clinical effectiveness and safety of vildagliptin in $>19000$ patients with type 2 diabetes: the GUARD study. Diabetes Obes Metab. 2015;17:603-607.

25. Cho YM, Kieffer TJ. New aspects of an old drug: metformin as a glucagon-like peptide 1 (GLP-1) enhancer and sensitizer. Diabetologia. 2011;54:219-222.

26. Liu L, Liu J, Huang Y. Protective effects of glucagon-like peptide 1 on endothelial function in hypertension. J Cardiovasc Pharmacol. 2015;65:399-405.

27. Sufiun A, Rafiq K, Fujisawa Y, Rahman A, Mori H, Nakano D, et al. Effect of dipeptidyl peptidase-4 inhibition on circadian blood pressure during the development of salt-dependent hypertension in rats. Hypertens Res. 2015;38:237-243.

28. Shah Z, Pineda C, Kampfrath T, Maiseyeu A, Ying Z, Racoma I, et al. Acute DPP-4 inhibition modulates vascular tone through GLP-1 independent pathways. Vascul Pharmacol. 2011;55:2-9.

29. Arca M, Pigna G, Favoccia C. Mechanisms of diabetic dyslipidemia: relevance for atherogenesis. Curr Vasc Pharmacol. 2012;10:684-686.

30. Nordestgaard BG, Benn M, Schnohr P, Tybjaerg-Hansen A. Nonfasting triglycerides and risk of myocardial infarction, ischemic heart disease, and death in men and women. JAMA. 2007;298:299-308.

31. Matikainen N, Mänttäri S, Schweizer A, Ulvestad A, Mills D, Dunning $B E$, et al. Vildagliptin therapy reduces postprandial intestinal triglyceride-rich lipoprotein particles in patients with type 2 diabetes. Diabetologia. 2006;49:2049-2057.

32. Hsieh J, Longuet C, Baker CL, Qin B, Federico LM, Drucker DJ, et al. The glucagon-like peptide 1 receptor is essential for postprandial lipoprotein synthesis and secretion in hamsters and mice. Diabetologia. 2010;53:552-561.
33. Song C, Burgess S, Eicher JD, O'Donnell CJ, Johnson AD. Causal Effect of Plasminogen Activator Inhibitor Type 1 on Coronary Heart Disease. J Am Heart Assoc. 2017;6:e004918.

34. Strózik A, Stęposz A, Basiak $M$, Drożdż $M$, Drożdż $B$. Multifactorial effects of vildagliptin added to ongoing metformin therapy in patients with type 2 diabetes mellitus. Pharmacol Rep. 2014;67:24-31.

35. Maeda S, Matsui T, Yamagishi S. Vildagliptin inhibits oxidative stress and vascular damage in streptozotocin-induced diabetic rats. Int J Cardiol. 2012;158:171-173.

36. Maeda S, Yamagishi S, Matsui T, Nakashima S, Ojima A, Maeda S, et al. Beneficial effects of vildagliptin on retinal injury in obese type 2 diabetic rats. Ophthalmic Res. 2013;50:221-226.

37. Hanefeld M, Frier BM, Pistrosch F. Hypoglycemia and cardiovascular risk: is there a major link? Diabetes Care. 2016;39:S205-S209.

38. Bodmer M, Meier C, Krähenbühl S, Jick SS, Meier CR. Metformin, sulfonylureas, or other antidiabetes drugs and the risk of lactic acidosis or hypoglycemia: a nested case-control analysis. Diabetes Care. 2008;31:2086-2091.

39. Kumar R, Kerins DM, Walther T. Cardiovascular safety of antidiabetic drugs, Eur Heart I Cardiovasc Pharmacother. 2016;2:32-43.

40. Kawanami D, Matoba K, Sango K, Utsunomiya K. Incretin-Based Therapies for Diabetic Complications: Basic Mechanisms and Clinical Evidence Int J Mol Sci. 2016;17:1223.

41. Farngren J, Persson M, Schweizer A, Foley JE, Ahrén B. Vildagliptin reduces glucagon during hyperglycemia and sustains glucagon counterregulation during hypoglycemia in type 1 diabetes. J Clin Endocrinol Metab. 2012;97:3799-3806.

42. Monami M, lacomelli I, Marchionni N, Mannucci E. Dipeptydil peptidase-4 inhibitors in type 2 diabetes: a meta-analysis of randomized clinical trials. Nutr Metab Cardiovasc Dis. 2010;20:224-235.

43. Karagiannis $T$, Paschos $P$, Paletas $K$, Matthews DR, Tsapas A. Dipeptidyl peptidase- 4 inhibitors for treatment of type 2 diabetes mellitus in the clinical setting: systematic review and meta-analysis. BMJ. 2012;344:e1369.

44. Valerio CM, de Almeida JS, Moreira RO, Aguiar L, Siciliano PO, Carvalho DP, et al. Dipeptidyl peptidase-4 levels are increased and partially related to body fat distribution in patients with familial partial lipodystrophy type 2. Diabetol Metab Syndr. 2017;9:26. 